\title{
ENTREVISTA
}

\section{ENAP: aqui se constroem aprendizes de estadista}

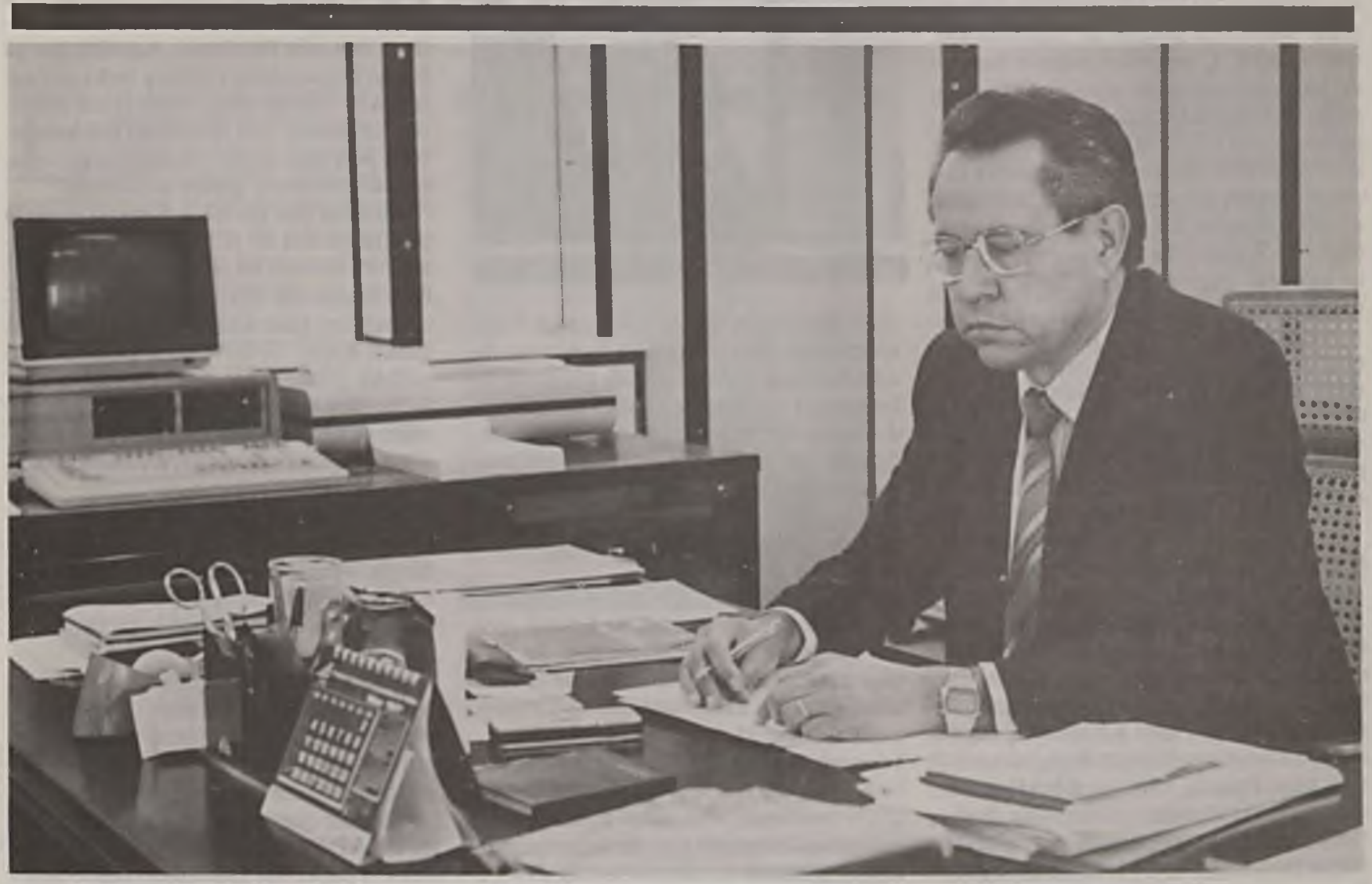

Estadista se faz na escola? Para o economista e administrador Nilson Holanda, diretor da Escola Nacional de Administração Pública - ENAP - é possivel criar verdadeiros aprendizes de estadistas numa escola voltada para aperfeiçoar inovaçōes, instrumentos e mecanismos de ação governamental.

Foi para se tornar esta "sementeira" de lideres, administradores e futuros estadistas que surgiu a ENAP em 19 de setembro de 1986, uma escola superior de administração pública que se prepara agora para realizar o seu primeiro curso a nivel de mestrado. Serão cento e vinte vagas, em horário integral, abertas para funcionários com nivel de graduação e que terão no curriculo informaçōes de alto nivel sobre administração pública, Economia, Direito, Ciência Política.

\section{Um Profissional Polivalente}

O que nós queremos é aquele profissional polivalente, capaz de se tornar um assessor ministerial de alto nivel, e que tanto poderá atuar num ministério da área econômica, como da área social, porque ele terá informações completas de Direito, de Política, de Economia, que são todas ciências interligadas e imprescindiveis para o administrador do futuro.

A explicação é de Nilson Holanda, que afirma estar o Brasil pelo menos cinqüenta anos atrasado em relação ao que já se faz em formação de mão-de-obra administrativa na França, no Canadá, na Espanha, e outros paises.

- O nosso modelo para a ENAP é o francês, o mais famoso e o mais bem- sucedido hoje em dia. Acrescentamos à experiência francesa, as lições aprendidas na ENAP do Canadá, onde a administração é bem desenvolvida a nivel universitário, e aproveitamos também as experiências nacionais bem-sucedidas, como o aperfeiçoamento do funcionário no Itamaraty, nas Forças Armadas, na Escola de Administração Fazendária, na Escola Superior de Administração Postal, nos centros de treinamento do Banco do Nordeste, além de experiências em organizaçōes estaduais.

Um bom exemplo, segundo o diretor da ENAP, é aquele funcionário do Itamaraty, altamente especializado nos problemas de politica externa e administração em geral. "Este profissional é tão precioso para o Itamaraty que esta hoje, é uma casa onde existe o menor grau de rotati- 


\section{ENTREVISTA}

vidade de funcionários de alto nivel a cada mudança de ministro".

\section{Três Grupos}

Formar o funcionário comprometido com o serviço público, com a ética do serviço público e não um improvisador, é um dos objetivos da ENAP. Para isso, ela vai atuar sobre três grupos de funcionários qualificados. O primeiro grupo é formado por funcionários de nível de $D A S$, que serão os funcionários de carreira. Um segundo grupo é o formado por pessoal de confiança limitada, em geral técnicos e especialistas em diferentes setores. $\mathrm{O}$ terceiro grupo funcional é o grupo da confiança direta do ministro de Estado, como chefe de gabinete, secretário-geral, um grupo de rotatividade maior.

- O nosso objetivo é que, no futuro, apenas este terceiro grupo possa ser mudado no organograma da administração direta ou indireta, que vai se valer cada vez mais de profissionais qualificados de nivel técnico ou de nível de DAS. - Afirma Nilson Holanda.

\section{Uma Escola Não Convencional}

Os objetivos são ambiciosos, reconhece o diretor da ENAP. Afinal, criar uma escola não convencional, com caracteristicas muito próprias e especiais, voltada para a excelência, para a qualidade superior do administrador brasileiro, não é tarefa para poucos anos. A ENAP é um centro de recrutamento e formação de dirigentes de alto nível mas cujo vestibular busca prioritariamente a seleção de profissionais para o exercicio de funções públicas. Mas a ENAP não é só este centro. Ela é também um centro de alto nivel, tanto na questão dos requisitos de seleção de candidatos como em relação à espécie de ensino e treinamento ministrados, todos em nivel de pós-graduação especial.

- O que se pretende - diz Nilson Holanda - é assegurar à administração pública federal aquilo de que ela aparentemente tanto carece: competência, profissionalismo, eficiência e compromisso efetivo com o interesse público.

Mas a ENAP ainda não é só isso. Outro de seus objetivos é o do treinamento voltado para o trabalho prático. "A idéia é dar um sentido muito objetivo, muito pragmático ao ensino, considerando que o estudo e o conhecimento devem ser instrumentos racionais para a solução de problemas concretos de políticas governamentais. É preciso não dar apenas erudi-

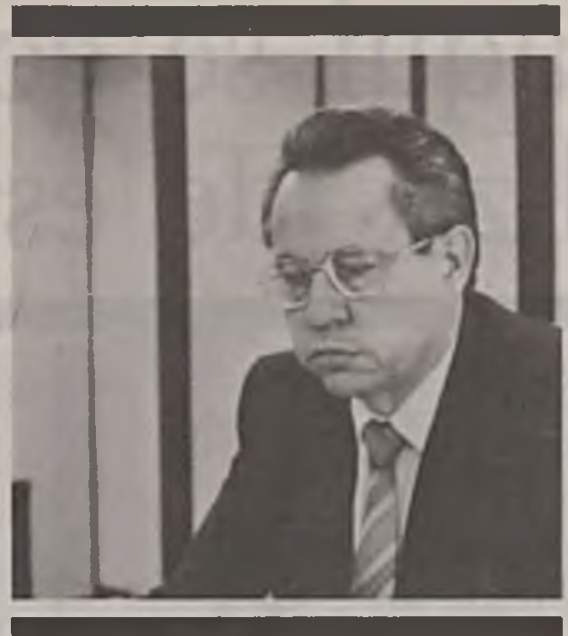

ção administrativa mas aprofundar o conhecimento das realidades e problemas da administração e da sociedade brasileira de forma que o dirigente público tenha condições de dar respostas prontas aos desafios de uma sociedade envolvida em profundos problemas sociais e econômicos".

\section{A Seleção de Alunos}

O ingresso aos cursos da ENAP será feito através de concurso público, de âmbito nacional, para brasileiros de ambos os sexos, com idade mínima de 23 anos e máxima de 35 anos, que possuam curso superior completo. O concurso será feito a nivel externo e interno com 40 por cento das vagas reservadas a candidatos já funcionários e 60 por cento aos candidatos externos.

A seleção dos candidatos será feita por um vestibular de três etapas, compreendendo dois exames prévios, realizados a nivel regional, e uma prova final em Brasília. No primeiro exame vai se avaliar o nivel geral de conhecimentos e cultura dos candidatos, que poderão responder questōes de múltipla escolha nas áreas de matemática, português, história e geografia, além de temas de direito, economia e organização social e política do Brasil.

O segundo exame envolve questōes discursivas sobre temas de economia, direito, ciência política e administração, além de uma língua estrangeira (inglês ou francês). Cada candidato escolhe uma matéria principal, que terá peso maior na avaliação final. O exame final será de caráter oral, perante uma banca examinadora, constituída por professores universitários, funcionários de alto escalão e convidados especiais, selecionados entre pes- soas de comprovado saber em sua área de atuação.

\section{A Estrutura de Ensino}

Como funcionará esta Escola de excelência administrativa? Ela é uma escola gratuita - explica Nilson Holanda - e todos os alunos receberão bolsas de estudo e moradia funcional. Aqueles que já forem funcionários públicos terão assegurados os seus direitos, como se em exercicio estivessem, não recebendo bolsa de estudo mas uma ajuda financeira para compensar eventuais gastos adicionais.

Em sua fase inicial, a duração total do programa será de 18 meses, incluindo estágios e um mês de férias. Além do curriculo básico em direito, economia e ciência política, haverá ainda seminários e pesquisas sobre formulação e avaliação da política pública, aprofundamento teórico - prático em ciências administrativas, e estágios supervisionados em órgãos públicos e empresas privadas, a nivel regional e nacional.

Os estágios serão desdobrados em três períodos de dois meses cada, da seguinte forma: estágio regional, estágio profissional em empresa pública ou privada, e estágio institucional em órgãos do Poder Legislativo e Judiciário.

Além disso, será ministrado em todo o curso o ensino de línguas (inglês, francês ou espanhol) e de outras matérias optativas, envolvendo temas complexos, que serão abordados de forma interdisciplinar.

É assim que o aluno de pós-graduação da ENAP tomará contato com assuntos como o papel das multinacionais, o federalismo brasileiro, o setor de empresas estatais, a crise energética, o diálogo NorteSul, sindicalismo e corporativismo no Brasil, divida externa e problemas regionais.

- Em síntese, toda a estratégia de ensino - conclui Nilson Holanda - está voltada para enfatizar o desenvolvimento da habilidade para pensar e da capacidade para decidir. De um lado, o profissional com uma visão crítica, científica e rigorosa, e de outro, o humanista, alguém preparado para enfrentar, no futuro, os desafios da gestão governamental, sem render-se ao conformismo, ao paroquialismo, à rotina ou ao desânimo. Verdadeiros aprendizes de estadista, dentro do modelo clássico mas sempre atual do Barão do Rio Branco, ainda hoje a inspirar a formação de novos quadros numa instituição que é modelar na administração pública brasileira, o Itamaraty. 